\title{
Métodos de Seleção de Pessoal: Discussões Preliminares sob o Enfoque do Behaviorismo Radical
}

Personnel selection methods:

Preliminary discussions under the approach of radical behaviorism
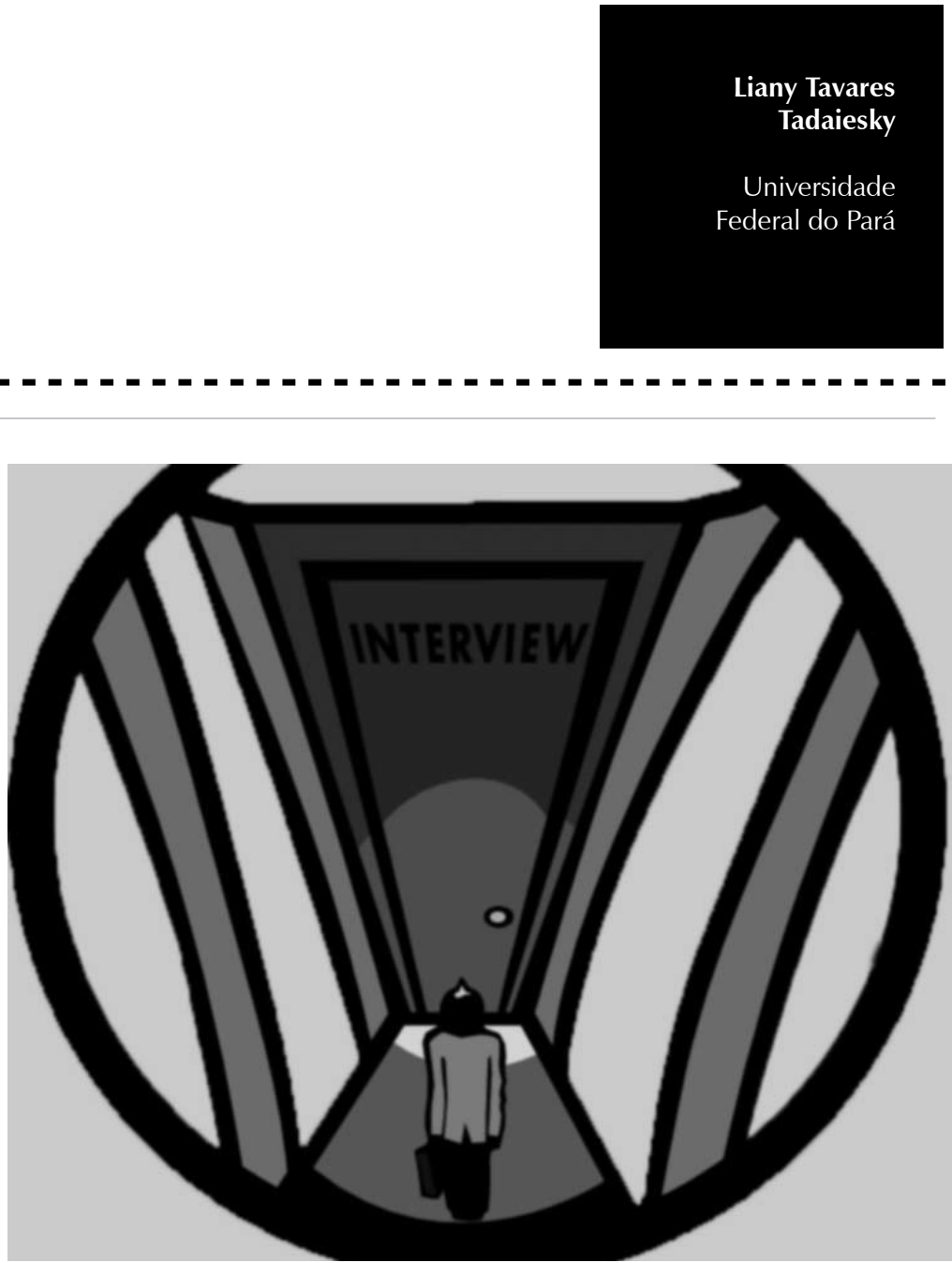
Resumo: A seleção de pessoal visa a introduzir na organização os candidatos mais apropriados as suas necessidades. Existe uma carência de literatura behaviorista radical acerca desse tema, sendo necessário o desenvolvimento de trabalhos que orientem atuações coerentes com essa teoria. $\mathrm{O}$ objetivo deste estudo é discutir os métodos utilizados na seleção à luz dos pressupostos conceituais do behaviorismo radical. Os métodos de seleção existentes são analisados e discutidos em termos de aumento do controle das variáveis presentes no contexto da seleção a fim de proceder à identificação dos repertórios comportamentais dos candidatos. Propõe-se uma análise de cargo baseada nos conceitos behavioristas, discute-se a possibilidade de condução de entrevistas de seleção focadas no comportamento bem como o uso de técnicas de simulação que permitam a identificação de repertórios comportamentais. Conclui-se que é necessário desenvolver discussões teóricas e instrumentos operacionais facilitadores de uma prática psicológica vinculada aos pressupostos behavioristas radicais.

Palavras-chave: Psicologia organizacional. Seleção de recursos humanos. Behaviorismo radical. Entrevistas.

\begin{abstract}
The goal of personnel selection is to introduce in the organization the applicant that best suits its needs. There is a lack of radical behaviorism literature concerning this subject, resulting in need of research intended to guide attitudes compliant with this theory. This paper discusses the selection methods according to the conceptual prepositions of radical behaviorism. Existing selection methods are analyzed and discussed in terms of increased control of variables present in the selection, in order to proceed to the applicant's behavioral repertory identification. A job analysis based on behaviorist concepts is proposed. The paper also discusses the possibility of conducting selection interview focused on behavior, as well as the use of simulation techniques that allow behavioral repertory identification. It concludes that theoretical discussions and operational instruments are necessary to the development of a psychological practice in accordance with a behaviorism model of personnel selection.
\end{abstract}

Keywords: Organizational psychology. Personnel selection. Radical behaviorism. Interview.

O foco da Psicologia organizacional é a organização como um todo, visando ao seu bom andamento. Spector (2003) acredita que a principal função do psicólogo organizacional é ampliar a eficácia e o funcionamento das organizações bem como propor melhorias ao ambiente de trabalho visando à satisfação dos funcionários, mesmo que isso não resulte diretamente em eficácia organizacional.

O raio de abrangência das atividades do psicólogo organizacional compreende tanto o desenvolvimento de pesquisas científicas quanto a resolução de problemas práticos. A atividade de pesquisa tem por objetivo investigar qual a melhor abordagem ou princípio para a resolução de um problema prático. Por outro lado, a parte prática da atuação de um psicólogo na empresa referese à aplicação de tais princípios no ambiente organizacional, com o intuito de alcançar e manter a eficácia dos processos desenvolvidos na empresa e a satisfação dos funcionários. Nesse sentido, apreende-se que o psicólogo organizacional é um cientista prático, pois concilia a pesquisa científica e a aplicação prática de princípios a problemas existentes no ambiente de trabalho (Spector, 2003).

Neste estudo, será dada maior ênfase à atividade de seleção de pessoal no que se refere aos conceitos e métodos de avaliação para a seleção de candidatos para uma organização. É importante ressaltar que esse 
Segundo

Chiavenato

(1999b), a seleção

de pessoal pode

ser vista como

um processo de

comparação

entre duas

variáveis: os

requisitos exigidos

para a execução das tarefas relacionadas

ao cargo vago e o perfil dos candidatos. campo de atuação profissional não é privativo de psicólogos, portanto, há uma vasta produção literária relativa ao tema que não está baseada em conceitos concernentes a quaisquer das abordagens psicológicas. Nesse sentido, a escolha da literatura para uma discussão inicial das práticas mais comuns na área da seleção de pessoal obedeceu, intencionalmente, ao critério de maior disseminação e uso pelos profissionais que atuam no meio, não sendo necessariamente produções da Psicologia. Pretende-se, pois, discutir as práticas de seleção de pessoal a partir das referências mais utilizadas pelos profissionais da área.

Chiavenato (1994) entende a seleção de pessoal como parte de um processo que tem por objetivo a contratação de novos funcionários ou o remanejamento de funcionários antigos para novos cargos. Tal processo é composto por cinco etapas consecutivas: recrutamento, triagem dos candidatos, seleção de pessoal, identificação de características pessoais e a integração na equipe; a fase de seleção de funcionários, portanto, tem início somente após o recrutamento e a triagem. O recrutamento consiste na divulgação da existência de vagas de emprego em uma determinada organização. O objetivo dessa fase é prover o processo seletivo de candidatos (Chiavenato, 1999b). A fase de triagem funciona como uma pré-seleção para reduzir o número de candidatos por vaga, permanecendo apenas aqueles que possuem os pré-requisitos para o cargo.

A seleção de pessoal caracteriza-se como o momento de tomada de decisão a respeito dos candidatos escolhidos. É uma atividade de classificação que visa essencialmente a introduzir no local de trabalho os candidatos mais apropriados às necessidades do cargo vago e da organização como um todo (Chiavenato, 1999b). Para quesejam avaliados os conhecimentos e as habilidades desejáveis nos candidatos, é necessário o levantamento de dados e informações a respeito do cargo a ser preenchido. Segundo Chiavenato (1999b), a seleção de pessoal pode ser vista como um processo de comparação entre duas variáveis: os requisitos exigidos para a execução das tarefas relacionadas ao cargo vago e o perfil dos candidatos.

A primeira etapa da seleção de pessoal corresponde à obtenção de informações relativas ao cargo a ser preenchido. Essa coleta de informações pode ser efetuada por meio da descrição e análise do cargo, etapa na qual são levantadas informações a respeito do conteúdo do cargo (aspectos intrínsecos) e dos requisitos necessários ao seu ocupante (aspectos extrínsecos). Nesse momento, são descritas tanto as tarefas desempenhadas nos cargos quanto as características humanas necessárias para o desenvolvimento das atividades. Tais características podem ser descritas em termos de conhecimentos, habilidades, aptidões e outras características pessoais, que compõem o denominado CHAOs (Spector, 2003). O conhecimento é definido como o que uma pessoa precisa saber para desempenhar um determinado trabalho; a habilidade, como aquilo que uma pessoa é capaz de realizar no trabalho, e a aptidão, como o talento ou a capacidade de uma pessoa para desempenhar tarefas ou aprendê-las, ou seja, o potencial para desenvolver habilidades.

Dessa forma, a análise de cargo tem dois focos, o trabalho e a pessoa. No primeiro, a análise é orientada ao cargo, enfocando as tarefas específicas da atividade e fornecendo informações sobre a natureza das tarefas realizadas no trabalho. Por outro lado, a análise orientada à pessoa preocupa-se com as características pessoais exigidas para um determinado trabalho. Essa análise fornece uma descrição dos atributos e das características pessoais ou CHAOs necessários para que uma pessoa desenvolva com sucesso um determinado trabalho (Spector, 2003). 
Chiavenato (2000) elenca alguns métodos utilizados com maior freqüência para a análise de cargos: a observação direta, o questionário e a entrevista direta. No método da observação direta, o analista de cargos efetua registros relacionados à observação dinâmica do atual ocupante do cargo em pleno exercício de suas atividades. No método do questionário, é solicitado aos executantes do cargo (ou mesmo seus supervisores) que preencham um questionário de análise de cargo, respondendo questões referentes ao conteúdo e às características do cargo, com o maior número de informações possíveis. Por fim, o método da entrevista consiste em reunir alguns elementos relativos ao cargo por meio de um contato direto do entrevistador com o ocupante ou seu chefe.

As informações adquiridas acerca do perfil do cargo são transformadas em uma ficha profissiográfica, na qual consta um resumo dos componentes das atividades efetuadas no cargo em questão. Ela também contém os atributos psicológicos e físicos necessários ao candidato ao cargo. A partir desses dados, podem ser estabelecidas as técnicas de seleção apropriadas para investigar a presença das características desejáveis nos candidatos (Chiavenato, 1999a, 1999b).

Entre as diversas técnicas de seleção de pessoal utilizadas, a entrevista é a mais empregada, e pode ser totalmente estruturada ou livre, conforme a experiência do entrevistador. Chiavenato (1999a) ressalta que é de extrema relevância que o entrevistador se livre de preconceitos e barreiras pessoais, no intuito de permitir a maior objetividade possível desse instrumento de seleção. Durante a entrevista, dois aspectos são essenciais para uma avaliação mais eficiente dos resultados: o conteúdo da entrevista e o comportamento do candidato. O conteúdo da entrevista é formado pelo conjunto de dados que o candidato relata a seu respeito, referentes à formação escolar, profissional, conhecimentos e interesses, entre outros; já o segundo aspecto constitui a maneira como o candidato age durante a situação de entrevista, isto é, as qualificações pessoais demonstradas no processo.

Os testes psicométricos também podem ser usados como instrumentos para a seleção de candidatos. Segundo Chiavenato (1999b), eles são considerados medidas objetivas e padronizadas de amostras de comportamentos e focalizam especificamente as aptidões dos candidatos. Os resultados individuais são comparados com padrões estatísticos, e, a partir disso, indicam em percentuais o quanto de cada tipo de aptidão existe no indivíduo. Esses testes procuram generalizar e prever aquela aptidão em determinadas formas de atuação profissional. Nesse contexto, Chiavenato (1999a) diferencia os conceitos de capacidade e aptidão, afirmando que aptidão é a potencialidade do indivíduo em aprender determinada habilidade, enquanto capacidade seria a habilidade atual da pessoa em relação a certa atividade. Desse modo, enquanto a aptidão é uma habilidade em estado latente que pode ou não ser desenvolvida, a capacidade é adquirida através do desenvolvimento dessa aptidão. Segundo o autor, a manifestação de determinadas habilidades ou capacidades depende da existência prévia de aptidões relacionadas a estas.

Além dos testes psicométricos, costuma-se utilizartambém ostestes de personalidade. Eles somente podem ser aplicados e interpretados por psicólogos, e têm como objetivo revelar características da personalidade dos candidatos. Chiavenato (1999b) conceitua personalidade como "... a integração única de características mensuráveis relacionadas com aspectos permanentes e consistentes de uma pessoa" (p. 123). Para ele, essas características podem ser determinadas pelo temperamento, caracterizando-se como inatas, ou adquiridas do meio. Os 
A teoria

behaviorista radical é

raramente citada como referencial para a atuação profissional no ambiente de trabalho, e, quando o é, costuma-se

abordá-la de modo superficial, não sendo exploradas todas as possibilidades de contribuição que essa abordagem pode oferecer. testes podem ser gerais, o que possibilita a formulação de um psicodiagnóstico total da pessoa, ou específicos, que investigam certos traços da personalidade dos candidatos.

Outro procedimento costumeiramente empregado nos processos de seleção são as técnicas de simulação, que são realizadas de forma grupal e devem ser conduzidas por um psicólogo ou um especialista no assunto (Chiavenato, 1999a). Nesse procedimento, os candidatos devem dramatizar uma situação qualquer, que levante questões pertinentes às habilidades exigidas para o desempenho do cargo disputado. O objetivo é averiguar os comportamentos característicos dos candidatos em interação com outras pessoas, partindo-se do princípio de que, durante a dramatização, a pessoa irá estabelecer vínculos e desempenhar os papéis habituais.

A partir do exposto, percebe-se que parte do arcabouço teórico existente sobre os conceitos, métodos e atividades comuns ao ramo da Psicologia organizacional, especialmente acerca do processo de seleção de pessoal, não estão pautados em uma abordagem psicológica específica. Esse campo de atuação parece estar mais voltado para o desenvolvimento de procedimentos práticos, não sendo enfatizadas construções teóricas baseadas em uma visão de mundo. $\mathrm{O}$ conhecimentoteóricoproduzidoapresenta, de modo pontual, uma visão internalista, pouco valorizando os fatores ambientais envolvidos na manifestação do comportamento em ambientes organizacionais.

A teoria behaviorista radical é raramente citada como referencial para a atuação profissional no ambiente de trabalho, e, quando o é, costuma-se abordá-la de modo superficial, não sendo exploradas todas as possibilidades de contribuição que essa abordagem pode oferecer. Alguns autores oferecem considerações condizentes com a análise do comportamento, porém tais considerações são, em geral, seguidas ou condicionadas a formulações mentalistas. Algumas críticas levantadas acerca do uso da análise do comportamento em ambientes de trabalho estão relacionadas, por exemplo, com os aspectos éticos, argumentando-se que as técnicas baseadas no behaviorismo visam à manipulação calculista dos indivíduos no ambiente de trabalho. Outra crítica à abordagem diz respeito à suposta elementaridade de seus princípios filosóficos, vistos como simples mecanismos estímulo-resposta que desconsideram os processos mentais e cognitivos envolvidos nos comportamentos humanos (Aguiar, 1980; Chiavenato, 1999b).

No entanto, entende-se que a abordagem behaviorista radical pode proporcionar subsídios para a atuação profissional do psicólogo na área organizacional, e, mais especificamente, para o processo de seleção de pessoal. Entretanto, conforme Santos, Franco e Miguel (2003), existe uma carência de produção bibliográfica nesse sentido, havendo a necessidade do desenvolvimento de trabalhos que apresentem parâmetros para uma atuação coerente com a análise do comportamento. Os autores ressaltam ainda que, em 20 anos de pesquisa na área de gerenciamento comportamental em organizações, não há sequer uma publicação sobre seleção de pessoal em uma perspectiva behaviorista, pelo menos nos periódicos mais importantes dessa área de atuação. Segundo Keenan (1995), existe pouca literatura sistematizada que ofereça informações a respeito de técnicas utilizadas em seleção bem como informações concernentes à efetividade desses procedimentos.

Santos et al. (2003) defendem a viabilidade de se utilizar fundamentos da análise do comportamento na identificação de indivíduos com os repertórios comportamentais mais adequados às características exigidas para um determinado cargo. Os autores afirmam que o 
analista do comportamento não irá considerar os estados internos como explicação do comportamento ou como justificativa para definir traços de personalidade. Seu objetivo será identificar e descrever as condições necessárias para que os comportamentos esperados possam ocorrer.

\section{Objetivo geral}

Discutir os métodos utilizados em processos de seleção de pessoal à luz dos pressupostos teórico-conceituais da abordagem behaviorista radical.

\section{Objetivos específicos}

Propor formas de manuseio e entendimento desses métodos a partir dos princípios da análise do comportamento.

Discutir as possibilidades de contribuições da abordagem behaviorista radical para a atuação profissional do psicólogo que atua em ambientes organizacionais, especialmente em processos de seleção.

\section{Considerações metodológicas}

Foi levantada parte da literatura bibliográfica existente a respeito dos conceitos e métodos pertinentes ao processo de seleção de pessoal, tendo sido utilizados como referência livros, capítulos de livros e artigos publicados em periódicos científicos.

Em virtude da área de atuação em recursos humanos não ser privativa de psicólogos, a pesquisa bibliográfica não se restringiu a fontes de cunho psicológico, mas também a produções voltadas especificamente para os procedimentos de seleção, desde que tais produções possuíssem reconhecimento e indicações freqüentes pelos profissionais da área.

Em seguida, procurou-se discutir os principais métodos descritos na literatura a partir de um enfoque teórico-conceitual condizente com a teoria behaviorista radical.

\section{Contribuições do behaviorismo radical para a seleção de pessoal}

Análise de cargo

A análise de cargo baseada na teoria comportamental deve ter como foco a investigação de contingências e comportamentos relacionados às principais tarefas do cargo em questão. Conforme os preceitos da análise do comportamento, a pesquisa deveestar respaldada por métodos objetivos e sistematizados que garantam alguma neutralidade e a validade dos resultados obtidos. Algumas estratégias podem ser utilizadas para levantar informações a respeito dos requisitos necessários ao candidato que desempenhará determinada função em uma organização. A literatura encontrada propõe alguns procedimentos, como observação direta, administração de questionário e entrevistas. Um modelo de análise de cargo comportamental pode fazer uso desses métodos, porém com algumas diretrizes.

\section{Observação em situação natural}

Na observação em situação natural, o analista de cargos deve estar atento às variáveis ambientais que exercem controle sobre os comportamentos manifestados pelo ocupante do cargo. Propõe-se aqui a realização de um registro cursivo dos comportamentos relevantes para o exercício da função, procedendo-se a descrições em termos de tríplices contingências. O número das sessões de observação efetuadas estará diretamente relacionado à complexidade das tarefas desempenhadas pelo ocupante do cargo de uma determinada organização. No entanto, é relevante que as sessões sejam distribuídas de modo a contemplar toda a gama das atividades executadas ao longo de um dia comum de trabalho. 
As primeiras sessões seriam válidas para proporcionar um panorama do cargo. Em seguida, propõe-se a construção de uma ficha de registro funcional do comportamento, na qual fossem discriminados os eventos antecedentes, os comportamentos e seus eventos conseqüentes. A partir de um registro cursivo, seria possível destacar as principais tarefas e comportamentos emitidos pelo funcionário, destacando-se os mais significativos a serem analisados funcionalmente. Uma ficha de registro funcional do comportamento é uma boa estratégia, na medida em que permite verificar a funcionalidade dos comportamentos emitidos pelo ocupante do cargo bem como a sua eficácia nas circunstâncias envolvidas.

Todavia, não é suficiente identificar o repertório comportamental exibido pelo ocupante do cargo, pois este pode não ser o mais adequado para as variáveis atuantes na organização. Nesse sentido, métodos que focalizem apenas os comportamentos do ocupante atual do cargo são problemáticos, pois, se o funcionário observado apresentar um repertório comportamental pouco adequado para o desempenho do cargo, haverá dificuldades em elencar as habilidades essenciais para o cargo desejado. Dessa forma, a análise dos eventos antecedentes e conseqüentes deve permitir ao psicólogo organizacional a descrição dos comportamentos mais adaptados às situações organizacionais observadas, independentemente de sua manifestação durante o registro. Averiguar a função do comportamento torna-se mais relevante do que descrever sua topografia, pois admite a identificação de classes de respostas efetivas para o contexto.

A observação em situação natural, entretanto, possui algumas desvantagens, pois capta apenas relações funcionais contíguas, ou seja, somente os eventos antecedentes e conseqüentes imediatos ao comportamento observado. Esse método não favorece a verificação de relações funcionais entre antecedentes e comportamentos temporalmente distantes e conseqüências a longo prazo.

\section{Questionários e entrevistas}

No que diz respeito ao uso de questionários e entrevistas, estes devem primar pela investigação das atividades típicas do cargo em questão e dos comportamentos necessários para realizá-las. A construção de um questionário requer do psicólogo organizacional uma noção prévia das tarefas desenvolvidas no cargo, pois esse instrumento deve conter as descrições operacionais das possíveis habilidades exigidas. $\mathrm{Na}$ medida em que esse procedimento tem cunho exploratório, deve ser abrangido o maior número de comportamentos passíveis de manifestação no contexto do cargo em análise e da organização como um todo.

O questionário não esclarece a função ou a topografia dos comportamentos requeridos, porém fornece um desenho das atividades desempenhadas segundo o próprio ocupante da vaga. Vale ressaltarque esse instrumento não tem como objetivo principal prover subsídios para a realização de análises contingenciais, e sim, propiciar uma enumeração dos comportamentos necessários, conforme a experiência do indivíduo que, a priori, está atuando sob o controle de variáveis relevantes no ambiente organizacional. Uma possibilidade interessante é a administração do questionário aos pares, subordinados e chefes do ocupante do cargo analisado, pois podem ser obtidas descrições complementares das tarefas e habilidades necessárias para o bom desempenho do funcionário.

Em relação à entrevista, pode-se dizer que ela possui finalidades semelhantes às do questionário, uma vez que se propõe a investigar as habilidades exigidas para o cargo a partir do relato do ocupante do cargo e de 
seu superior. Assim, como o questionário, ela não proporciona a observação dos comportamentos típicos do exercício do cargo em meio às suas contingências. Todavia, as perguntas podem ser direcionadas, a fim de que o entrevistado relate os comportamentos mais exigidos para o desempenho do cargo em termos de tríplice contingência. A partir disso, o analista de cargo poderia examinar o contexto em que os comportamentos são emitidos e a sua efetividade para a obtenção de conseqüências positivas para a organização e para o trabalhador.

Durante a entrevista, é importante verificar também as contingências operantes no ambiente organizacional como um todo, isto é, as condições de trabalho, a forma como as relações interpessoais são usualmente estabelecidas e algumas regras e vícios presentes na organização, entre outros aspectos. Portanto, é interessante que a entrevista não esteja restrita à descoberta de informações diretamente relacionadas ao cargo. Ela pode servir como instrumento para a análise do cargo em um nível contingencial maior, a fim de se elencar comportamentos promotores de conseqüências positivas.

Os métodos discutidos devem ser utilizados complementarmente, visto que apresentam focos diferenciados para a identificação dos elementos necessários a uma análise de cargo completa e bem-sucedida.

A partir das informações levantadas na análise de cargos, costuma-se elaborar uma lista das habilidades necessárias ao futuro ocupante do cargo. Na medida em que este texto tem como escopo discutir as estratégias de seleção de pessoal a partir de um enfoque behaviorista radical, propõe-se que essas habilidades individuais desejadas sejam definidas em termos de operacionalizações comportamentais. Taisdefiniçõesoperacionais devem ser estabelecidas em termos de tríplice contingência, a fim de que o psicólogo organizacional possa melhor identificar as variáveis das quais cada comportamento requerido é função.

\section{Seleção dos candidatos}

\author{
Testes psicológicos
}

Uma questão controversa presente nos processos de seleção de pessoal diz respeito ao uso de testes psicológicos. A maioria deles foi criada para medir aptidões, inteligência e traços de personalidade, procedendose a classificações dos indivíduos por meio de rótulos que desconsideram diferenças individuais e variáveis ambientais (Noronha, 2002; Santos et al., 2003) . Para Wanderley (1985), o sucesso no desempenho profissional depende também das circunstâncias organizacionais em que as tarefas são realizadas, como condições de trabalho, clima organizacional e incentivos comportamentais existentes, entre outras particularidades. Segundo o autor, a medição de características psicológicas através de testes implica aceitar a tese de que existem processos mentais, representados pelos escores, que governam a atuação do indivíduo. Do ponto de vista da análise do comportamento, essa noção é internalista, e, como tal, ignora variáveis ambientais significativas para a emissão de comportamentos mais e menos adequados pelos candidatos.

De acordo com Noronha (2002), muitos testes são criticados por não serem adequados à realidade brasileira. Outro ponto importante destacado pela autora está relacionado à precariedade na formação profissional do psicólogo no que concerne à aplicação de testes, o que ocasiona freqüentemente um uso "mecânico" e inadequado do instrumento. Segundo Skinner (1981), o teste permite a observação do comportamento, porém suas descrições, em termos de traços, impedem a determinação do que o indivíduo fez e em que condições ambientais, uma vez que, em geral, objetivam classificar características permanentes do indivíduo. Para o autor, "a previsão do que um indivíduo médio fará é, freqüentemente, de pouco ou nenhum valor ao se tratar com um indivíduo particular" (p. 
É importante notar que comportamentos não-verbais do entrevistador podem controlar as respostas verbais e nãoverbais do entrevistado.
31). Desse modo, estatísticas referentes ao conjunto de uma sociedade desconsideram variáveis ambientais estabelecedoras de diferenças individuais.

Assim, a utilização de testes projetivos ou inventários pode apresentar limitações no sentido de não estabelecer contingências efetivasparaaocorrênciadoscomportamentos requeridos, não sendo possível verificar se esses estão presentes ou não no repertório do candidato. Segundo Wanderley (1985), não existem pesquisas que comprovem as potencialidades preditoras dos vários tipos de testes utilizados em ambientes organizacionais para a seleção de pessoal.

Sackette Lievens (2008) afirmam que testes de habilidade ou personalidade proporcionam apenas sinais de comportamentos possivelmente efetivos no ambiente de trabalho, visto que lidam com habilidades e predisposições descontextualizadas das atividades laborais. Por outro lado, técnicas que envolvam a manifestação direta de comportamentos, como simulações, são mais consistentes, pois são baseadas na dramatização de comportamentos desejáveis para o desempenho do cargo. Assim, para uma seleção baseada na análise do comportamento, é mais eficaz a adoção de técnicas que propiciem a interação com o candidato, captando-o em ação, do que o uso de testes que supostamente definem a personalidade do indivíduo.

\section{Entrevista analítico-comportamental}

Conforme Monti (2005), a entrevista é o instrumento soberano nos processos de seleção de pessoal, sendo a técnica de seleção mais usada nos meios profissionais. Para a autora, a entrevista é um momento de troca de informações entre entrevistador e entrevistado, no qual o primeiro lança estímulos verbais no ambiente que the permitem estudar as repostas verbais e nãoverbaisdoentrevistado. Noentanto, emvirtude da subjetividade freqüentemente presente nesse tipo de técnica, é imprescindível que sejam tomadas precauções a fim de impedir que variáveis não controladas e indesejáveis interfiram na seleção (Monti, 2005).

De acordo com a autora, tanto o entrevistador quanto o entrevistado estão sujeitos à influência de variáveis externas ao processo de entrevista em si. O local da entrevista, as possíveis interrupções e até mesmo eventos encobertos podem ser variáveis controladoras durante a entrevista. É essencial, pois, que o entrevistador participe de um treinamento adequado, objetivando-se assim reduzir a influência de variáveis estranhas durante a entrevista de seleção. É importante notar que comportamentos não-verbais do entrevistador podem controlar as respostas verbais e nãoverbais do entrevistado. Assim, a expressão facial e corporal diante das observações do candidato e o tom de voz utilizado, entre outros aspectos, devem ser observados (Monti, 2005).

Durante a entrevista, devem ser analisados também os comportamentos não-verbais do entrevistado, verificando-se a existência ou não de sincronia entre esses comportamentos e o relato verbal. De modo geral, costuma ser necessário que o candidato demonstre confiança, segurança, assertividade e simpatia, entre outras características. Estas podem ser averiguadas por meio de comportamentos não-verbais, como postura corporal firme, contato visual, gestos articulados, entonação de voz adequada, modulação da voz, sorrir em momentos apropriados, etc.

Nas entrevistas tradicionais, costuma-se focalizar aspectos relativos a preferências pessoais, responsabilidades e conhecimento do trabalho, entre outros pontos (Maurer \& Fay, 1988). De acordo com Barclay (2001), essas perguntas relacionadas a opiniões, autoavaliação, objetivos e aspirações do candidato são fracas, pois permitem que o indivíduo se apresente de forma demasiadamente favorável, evitando a revelação de seus pontos 
fracos. Campiom, Palmer e Campiom (1997) acreditam que as questões tradicionais não são baseadas em uma análise de cargo, e são aplicadas indistintamente. Elas costumam se centrar mais em traços da personalidade ou em aspectos que os entrevistadores acreditam ser relevantes, independentemente das particularidades do cargo a ser preenchido.

Essa prática está presente na maioria das organizações, que buscam informações relativas a qualidades pessoais ou a características gerais desejáveis em qualquer trabalhador, não levando em consideração a investigação de habilidades especificamente relacionadas ao emprego, conforme o delineamento que pode ser feito pela análise do cargo (Keenan, 1995). Esse tipo de estratégia não analisa as contingências operantes sobre os futuros comportamentos a serem emitidos pelo candidato, resultando, muitas vezes, em um processo de seleção ineficaz.

Um modelo de entrevista analíticocomportamental deve atentar para a identificação dos comportamentos presentes no repertório do candidato, das contingências nas quais estes são emitidos e dos reforços aos quais esse indivíduo é sensível. As perguntas elaboradas devem ter como objetivo identificar no relato verbal e na comunicação não-verbal do candidato a existência dos comportamentos listados como desejados para o desempenho do cargo. O entrevistador deve ter habilidade para fazer emergir no relato do candidato descrições de situações em termos de tríplices contingências.

Segundo Monti (2005), na década de 70 , foi elaborado um modelo de entrevista denominado entrevista comportamental. Nesse tipo de entrevista, o foco é o comportamento passado do candidato em um ambiente de trabalho, sendo requerida dos candidatos a descrição de situações nas quais exibiram comportamentos condizentes com as habilidades desejáveis para o cargo que estão disputando. A entrevista comportamental baseia-se no pressuposto de que o comportamento passado prediz o comportamento futuro. Nesse sentido, o entrevistador deve tentar identificar, nas situações relatadas pelo candidato, evidências comportamentais das habilidades que investiga. Estariam sendo analisadas as ocasiões em que o indivíduo obteve sucesso em emitir um determinado comportamento, ou seja, as contingências de reforçamento operantes.

Sob uma perspectiva behaviorista radical, os dados obtidos a partir desse tipo de entrevista possibilitariam a análise funcional do comportamento relatado, pois o entrevistador deve identificar, no relato verbal do candidato, especificamente nas descrições de comportamentos ocorridos no passado, os eventos antecedentes que determinaram seu comportamento, a resposta em si e as suas conseqüências (Monti, 2005). A principal vantagem da entrevista comportamental é o fator de dificuldade que ela traz para um relato irreal sobre as habilidades do candidato, uma vez que ele deve descrever situações consistentes sobre comportamentos passados, relacionando coerentemente o contexto, a ação tomada e os resultados oriundos. Isso evitaria a emissão de respostas "prontas" e pouco fidedignas (Barclay, 2001; Monti, 2005). De fato, algumas pesquisas sugerem que, quanto mais estruturada a entrevista, menor a probabilidade de respostas pouco fidedignas pelos candidatos (Sackett \& Lievens, 2008).

Uma questão importante relacionada a esse modelo de entrevista diz respeito aos candidatos com pouca ou nenhuma experiência profissional prévia. $\mathrm{Em}$ tal situação, relatos verbais de comportamentos passados relacionados às habilidades desejadas ao desempenho do cargo estariam impossibilitados. Monti (2005) sugere que os comportamentos indicadores das habilidades requeridas podem ser identificados no relato verbal da história pessoal do indivíduo, ou 
seja, em situações fora de um contexto de trabalho. Barclay (2001) discute também a possibilidade de descrição de experiências não relacionadas a ambientes de trabalho, proporcionando ao candidato maior oportunidade de demonstrar sua adequação ao cargo.

Entretanto, devem ser tomados certos cuidados com esse tipo de abordagem, uma vez que os estímulos discriminativos operantes em contextos organizacionais não são necessariamente os atuantes em situações distintas. Assim, comportamentos de liderança, por exemplo, podem estar presentes em ambientes familiares, porém ausentes em ambientes de trabalho. $\mathrm{Na}$ pesquisa conduzida por Barclay (2001) acerca do uso da entrevista comportamental em organizações do Reino Unido, a principal queixa encontrada está relacionada ao uso dessa técnica com candidatos sem experiência profissional prévia. O autor relata que os entrevistadores referiram dar menos importância a descrições de experiências ocorridas em contextos diferentes do ambiente de trabalho.

Outro modelo de entrevista ainda pouco utilizado em processos de seleção de pessoal é a entrevista situacional. Nesse modelo, são propostas situações hipotéticas que podem ocorrer no exercício do cargo, sendo inquiridos dos candidatos como eles agiriam mediante tais contextos (Barclay, 2001; Maurer \& Fay, 1988). De acordo com Latham e Saari (1984), a premissa básica dessa entrevista consiste na crençadequeasintençõeseoscomportamentos das pessoas estão relacionados.

As situações propostas são construídas a partir das tarefas e habilidades consideradas necessárias ao desempenho da função, informações essas levantadas por meio da análise de cargo. A partir dessa análise, são elaborados exemplos de comportamentos possíveis de emissão na situação proposta, os quais podem variar em uma escala relativa à adequabilidade e efetividade destes. As respostas dos candidatos devem ser comparadas e enquadradas conforme os itens previamente elaborados (Latham \& Saari, 1984; Maurer \& Fay, 1988).

A partir de um enfoque analíticocomportamental, pode-se dizer que a entrevista situacional proporciona a descrição de contingências possíveis de serem enfrentadas no ambiente de trabalho, sendo esperado dos candidatos o relato dos comportamentos que poderiam ser emitidos mediante tais estímulos. Parte-se do pressuposto de que o candidato estaria relatando comportamentos presentes em seu repertório comportamental e de mais provável emissão na presença dos estímulos relatados pelo entrevistador. Nesse sentido, a análise do candidato a respeito de quais comportamentos manifestaria nas condições apresentadas estaria condicionada à sua história prévia em contingências similares. O indivíduo deveria estar consciente dos comportamentos comumente emitidos, ou seja, presentes em seu repertório comportamental em situações que possuam propriedades discriminativas ou reforçadoras semelhantes.

Todavia, um aspecto a ser discutido em relação a essa técnica diz respeito à correspondência entre o relato verbal do candidato e os comportamentos realmente emitidos nas situações hipotetizadas. Conforme Pergher (2002), o comportamento verbal é emitido sob o controle de um estímulo discriminativo, ao qual nem sempre o ouvinte tem acesso. O autor descreve pesquisas conduzidas por Critchfield e Perone (1993 citado por Pergher, 2002, p. 113), nas quais os participantes deveriam responder a quantidade de erros e acertos em uma determinada tarefa. Constatou-se que os sujeitos tenderam a dizer que acertaram mesmo quando haviam errado. Pergher (2002) observa, portanto, que os relatos falsos se voltavam freqüentemente na direção de comportamentos socialmente desejáveis. Assim, relatos seguidos de 
Os

experimentadores concluíram que as crianças estavam vivenciando uma contingência de esquiva, na qual não poderiam começar a brincar até que verbalizassem algo aceitável pelo experimentador. conseqüências aversivas têm maior probabilidade de serem falsos. De acordo com Meyer (2005), os relatos verbais podem ser determinados não apenas pelos estímulos que descrevem, mas também por outras variáveis ambientais. Nesse caso, o relato verbal de um indivíduo poderia estar sob controle de suas conseqüências, e não de condições antecedentes.

Em um experimento conduzido por Baer e Detrich (1990 citado por Pergher, 2002, p. 116), no qual crianças deveriam dizer com quais brinquedos iriam brincar e em seguida poderiam escolher livremente entre uma variedade de brinquedos. Na primeira fase, havia uma correlação precisa entre o dito e o feito, porém, em outra fase do experimento, as crianças somente poderiam escolher entre opções restritas de brinquedos (os quais haviam tido baixa freqüência de uso por elas em sessões anteriores). Nessa fase, as crianças verbalizavam que brincariam com um dos brinquedos selecionados, porém acabavam por brincar com os brinquedos de sua preferência. Os experimentadores concluíram que as crianças estavam vivenciando uma contingência de esquiva, na qual não poderiam começar a brincar até que verbalizassem algo aceitável pelo experimentador.

De modo análogo, discute-se a possibilidade de o relato verbal do candidato à seleção para uma determinada organização estar sob controle das conseqüências, e não das condições antecedentes. Assim, haveria uma alta probabilidade de o indivíduo emitir um relato falso, porém reforçado positivamente pelo ouvinte através, por exemplo, da contratação. Estímulos antecedentes como a história prévia do candidato e a consciência dos comportamentos disponíveis em seu repertório podem não estar controlando suas respostas verbais no momento da entrevista situacional. Seria, pois, interessante desconfiar das verbalizações do indivíduo, mobilizandose para buscar outras contingências que confirmem o relato verbal (Pergher, 2002).
Mauren e Fay (1988) sugerem que a entrevista comportamental e a entrevista situacional sejam utilizadas em conjunto, uma vez que possibilitam a investigação de comportamentos passados e prováveis comportamentos futuros. Os autores propõem que inicialmente se verifique com o candidato exemplos de situações nas quais ele tenha se comportado da maneira desejada, conforme as premissas da entrevista comportamental. No caso de o candidato negar a vivência da situação perguntada, o entrevistador poderia manter a questão trabalhando-a em termos de hipóteses, conforme a proposta da entrevista situacional. Assim, a entrevista situacional pode ser mais apropriada para candidatos que possuem pouca ou nenhuma experiência profissional prévia (Barclay, 2001).

Comparando-se as entrevistas tradicionais, tanto a entrevista comportamental quanto a situacional trazem grandes contribuições e avanços para uma atuação profissional mais vinculada aos pressupostos da análise do comportamento. Estas são mais eficazes em virtude de o foco estar nos comportamentos do candidato em si, e não em "sinais" de comportamentos, como as características internas do indivíduo. Conforme alguns autores propõem (Barclay, 2001; Mauren \& Fay, 1988), esses dois tipos de entrevista podem ser utilizados complementarmente, de modo que se possa identificar do modo mais completo possível o repertório comportamental do candidato entrevistado.

Além disso, as demais técnicas de seleção de pessoal discutidas devem ser utilizadas, a fim de que sejam estabelecidas diversas contingências que propiciem a emissão ou a descrição dos comportamentos dos candidatos em situações possíveis de serem enfrentadas no ambiente de trabalho.

\section{Técnicas de simulação}

De acordo com a análise do comportamento, todo comportamento deve ser analisado dentro de um contexto, ou seja, em termos 
de tríplices contingências. Não basta verificar se determinados comportamentos estão presentes no repertório comportamental de um indivíduo, devendo-se observar também quais as variáveis que ocasionam suas emissões e quais as que os mantêm. Relatos verbais de comportamentos passados apenas indicam maior probabilidade de ocorrência em situações futuras. É importante que o repertório comportamental atual do candidato seja analisado diretamente; desse modo, para o modelo behaviorista de seleção de pessoal discutido no presente estudo, observar diretamente o candidato em meio a contingências semelhantes às dispostas na organização através de técnicas de simulação pode ser útil para identificar seu repertório comportamental.

De acordo com Bruno (2005), somente esse tipo de estratégia permitiria entender o que as pessoas fazem e porque o fazem. Para o autor, o processo avaliativo deve ser dinâmico, possibilitando a identificação dos recursos utilizados pelos candidatos para obter bons resultados. Segundo Santos et al. (2003), alguns métodos já utilizados por profissionais da área, a exemplo de exercícios situacionais e amostras de trabalho, podem ser úteis para verificar a existência de comportamentos específicos nos repertórios dos candidatos, uma vez que podem envolver contingências similares às que serão vivenciadas no desempenho do cargo.

Desse modo, o refinamento dos métodos comumente usados, a partir de uma ênfase na compreensão do comportamento como produto das variáveis ambientais, pode propiciar o uso das técnicas de simulação conforme as proposições teórico-conceituais da análise do comportamento. Assim, os candidatos receberiam instruções da situação que será dramatizada e da tarefa que deverão desempenhar, podendose verificar o repertório comportamental que o candidato disponibiliza para as contingências estabelecidas. Seria importante que o candidato não dispusesse de tempo para a preparação da simulação, a fim de se evitar a manifestação de comportamentos pouco espontâneos e de improvável emissão em um contexto de trabalho natural. É interessante também que, após a simulação, sejam feitas algumas perguntas aos candidatos sobre os motivos dos comportamentos emitidos, o que permitiria uma identificação mais eficaz a respeito das variáveis operantes.

Bruno (2005) critica o uso dessa técnica argumentando sobre a artificialidade da situação dramatizada, visto que é uma prática comum o emprego de situações atípicas e bastante divergentes do cotidiano dos candidatos. Essa crítica é válida, pois o ideal seria arranjar contingências bastante semelhantes às encontradas na organização, a fim de se evitar que os comportamentos manifestados pelos candidatos nas situações de teste estejam sob o controle de variáveis que não serão enfrentadas no ambiente de trabalho. Dessa forma, a manipulação de variáveis que possibilitem o arranjo de contingências similares às futuramente enfrentadas pelo candidato no ambiente de trabalho pode ser mais eficaz como estratégia de avaliação.

Barclay (2001) argumenta ainda que os demais participantes da simulação provavelmente não apresentam os mesmos comportamentos e habilidades que os membros da equipe com que o candidato se relacionará futuramente. O autor ressalta ainda o fato de que a rápida visão dos comportamentos do candidato permitida por essa técnica não representa a totalidade dos comportamentos que podem ser emitidos em situações semelhantes.

A despeito da pertinência dessas críticas feitas às técnicas de simulação, acredita-se que a observação direta dos comportamentos dos candidatos é um trunfo que não pode ser ignorado pelo psicólogo organizacional que utiliza os pressupostos da análise do comportamento em sua atuação profissional. 
Nesse sentido, devem-se manipular variáveis de modo que as situações dramatizadas de fato forneçam subsídios confiáveis para a identificação do repertório comportamental dos candidatos, devendo-se necessariamente proceder à análise das variáveis das quais os comportamentos manifestados éfunção, a fim de se obter análises funcionais completas.

Além das técnicas presentemente discutidas, outras poderiam ser utilizadas em processos de seleção de pessoal. A elaboração de técnicas condizentes com a abordagem behaviorista radical pode ser mais bem discutida a partir de pesquisas empíricas realizadas em ambientes organizacionais, particularmente voltadas para projetos de seleção. Cabe observar ainda que outras formas de manuseio das técnicas já existentes podem ser discutidas em estudos posteriores, uma vez que a prática profissional de psicólogos atuantes em ambientes de trabalho proporciona inúmeras contribuições para discussões teóricas a respeito de seleção de pessoal.

\section{Considerações finais}

Discutir um modelo de seleção de pessoal behaviorista radical implica diversas dificuldades, uma vez que há pouca produção literária na área que possibilite um enfoque à luz dessa teoria. No que diz respeito à atuação do psicólogo organizacional em processos de seleção de pessoal, pode-se afirmar que, de modo geral, os pressupostos comportamentais não têm sido utilizados como fundamento para a prática cotidiana desse profissional.

Existe certa separação entre as diferentes possibilidades de aplicação dos conhecimentos oriundos da Psicologia. Segundo Sampaio (1998), as práticas próprias da Psicologia aplicadas a ambientes de trabalho costumam ser vistas como estranhas a essa área de conhecimento. De modo análogo, alguns conhecimentos típicos dessa ciência podem ser considerados incompatíveis com $\mathrm{O}$ ramo de atuação referido. Essa questão dificulta a formação profissional adequada de um profissional atuante em ambientes organizacionais bem como a penetração dos pressupostos filosófico-conceituais das diversas abordagens psicológicas nesse campo de atuação.

A formação do psicólogo organizacional costuma ser relegada a um segundo plano nas grades curriculares dos cursos de Psicologia, sendo priorizada a atuação clínica em detrimento das demais habilitações (Bastos \& Martins, 1990; Sampaio, 1998). Isso representa uma contradição, uma vez que, segundo Bastos e Martins (1990), a Psicologia organizacional é a segunda área que absorve um maior contingente de psicólogos, havendo inclusive um acelerado recrudescimento da procura por psicólogos habilitados a atuar neste ambiente.

Em virtude disto, a produção teórica relativa à Psicologia organizacional é relativamente recente na história da Psicologia. Pode-se dizer que as conceituações e elaborações teóricas necessárias para subsidiar a prática do profissional que se ampara na análise do comportamento não estão acompanhando e suprindo as questões emergentes nesse ramo de atuação. De modo geral, o profissional encontra-se desamparado de instrumentos metodológicos condizentes com a noção filosófica e conceitual do behaviorismo radical. Existe, pois, uma necessidade premente de discussões teóricas e de desenvolvimento de instrumentos operacionais, voltados para as especificidades do ambiente de trabalho que permitam uma prática vinculada à abordagem analítico-comportamental.

Nesse sentido, procurou-se fazer uma discussão inicial acerca das possibilidades de se realizar trabalhos no campo da Psicologia organizacional a partir de um enfoque comportamental, especificamente no que se refere à seleção de pessoal. 
A relação direta existente entre a escolaridade dos sujeitos e a manutenção dos conteúdos políticos na memória social da população apareceu de forma clara e inequívoca tanto na amostra dos idosos quanto na dos adultos.
Obviamente, este trabalho não teve como objetivo esgotar o tema, uma vez que possui um caráter eminentemente teórico e exploratório. Não foram feitas também considerações a respeito do acompanhamento do desempenho do candidato selecionado na organização. A partir de uma perspectiva analíticocomportamental, podem ser discutidas ainda manipulações de contingências que aumentem a probabilidade de emissão dos comportamentos desejáveis. Estudos teóricos e empíricos acerca desse acompanhamento do candidato na organização são necessários, visto que permitem a validação das técnicas empregadas no processo de seleção de pessoal.

Todos os métodos foram discutidos com o objetivo de aumentar o controle das variáveis presentes no contexto da seleção de pessoal. Uma das conseqüências é o estabelecimento de um processo seletivo mais justo para os candidatos, além da proposição de instrumentos que permitam uma escolha mais bem sucedida para a organização e a satisfação do indivíduo selecionado. Na realidade, a satisfação do candidato, aprovado ou não, com o processo de seleção pode fornecer uma medida do grau de justiça atribuído à seleção. Segundo Sackett e Lievens (2008), simulações e entrevistas são percebidas de modo mais favorável pelos candidatos do que testes de habilidade e personalidade. Esses dados evidenciam certa abertura no campo da Psicologia organizacional para o emprego de métodos e técnicas baseados em comportamentos, os quais acabam por serem considerados mais justos em virtude do maior grau de objetividade característicos desses procedimentos.
Dessa forma, um enfoque analíticocomportamental irá necessariamente manipular variáveis no sentido de investigar comportamentos, eventos antecedentes e conseqüentes eficazes, seja por meio de entrevistas, questionários, observações ou técnicas de simulação. No entanto, é válido ressaltar que, no contexto de uma ciência do comportamento baseada em pressupostos filosóficos como o multideterminismo, pode-se falar apenas em probabilidades. Nenhuma técnica irá reproduzir as exatas contingências presentes no ambiente de trabalho, assim como nenhum comportamento manifestado ou relatado pelos candidatos proporcionará uma garantia indubitável de emissão futura. Todavia, pode-se dizer que o uso de técnicas que focalizem comportamentos e variáveis ambientais durante o processo de seleção aumentam fortemente a probabilidade de se escolher um candidato com o repertório comportamental mais completo para as necessidades da organização e com maior probabilidade de satisfação em meio às contingências presentes.

A abordagem behaviorista radical deve fornecer subsídios para a atuação do psicólogo organizacional. Este trabalho teve a intenção de iniciar discussões a respeito das técnicas utilizadas em processos seletivos, pois é através dessas análises que se pode melhor elaborar a seleção de pessoal, com vistas a um processo eficaz e condizente com os conhecimentos teóricos do behaviorismo radical. É importante que estudos posteriores demonstrem a eficácia das técnicas discutidas, desenvolvendo novos procedimentos e métodos que permitam uma utilização eficiente dos conceitos da análise do comportamento. 


\section{Referências}

\section{Liany Tavares Tadaiesky}

Psicóloga, Mestranda do Programa de Pós-Graduação em Teoria e Pesquisa do Comportamento da Universidade Federal do Pará (UFPA).

E-mail: liatadaiesky@oi.com.br

Endereço para correspondência:

Avenida João Paulo II, 285, Marco Cep: 66095-490, Belém-PA

Recebido 04/04/07 Reformulado 05/01/08 Aprovado 16/01/08

Aguiar, M. (1980). Psicologia aplicada à administração: uma introdução à Psicologia organizacional. São Paulo: Atlas.

Barclay, J. M. (2001). Improving selection interviews with structure: Organizations' use of "behavioral" interviews. Personnel Review, 30(1), 81-101.

Bastos, A., \& Martins, A. (1990). O que pode fazer o psicólogo organizacional. Psicologia: Ciência e Profissão, 1, 10-18.

Bruno, L. (2005). Selecionar por competências. In A. Néri, (Ed.) Gestão de RH por competências e empregabilidade. (2a ed. rev. e atual.). Campinas, SP: Papirus.

Campiom, M. A., Palmer, D. K., \& Campiom, J. E. (1997). A review of structure in the selection interview. Personnel Psychology, 50(3), 655-702.

Chiavenato, I. (1994). Gerenciando pessoas. São Paulo: Makron Books.

Chiavenato, I. (1999a). Planejamento, recrutamento e seleção de pessoal: como agregar talentos à empresa. (4a ed.) São Paulo: Atlas.

Chiavenato, I. (1999a). Gestão de pessoas: o novo papel dos recursos humanos nas organizações. Rio de Janeiro: Campus.

Chiavenato, I. (2000). Recursos humanos. (6a ed. comp.). São Paulo: Atlas, 2000.

Keenan, T. (1995). Graduate recruitment in Britain: A survey of selection methods used by organizations. Journal of Organizational Behavior, 16(4), 303-317.

Latham, G. P., \& Saari, L. M. (1984). Do people do what they say? Further studies on the situational interview. Journal of Applied Psychology, 69(4), 569-573.

Maurer, S. D., \& Fay, C. (1988). Effect of situational interviews, conventional structured interviews and training on interview rating agreement: An experimental analysis. Personnel Psychology, 41(2), 329-344.
Meyer, S. (2005). Regras e auto-regras no laboratório e na clínica. In J. Rodrigues \& M. Ribeiro (Eds), Análise do comportamento: pesquisa, teoria e aplicação. Porto Alegre: Artmed.

Monti, R. S. G. (2005). O comportamento verbal na entrevista comportamental em seleção. In A. Néri (Ed.), Gestão de RH por competências e empregabilidade. (2a ed. rev. atual.). Campinas, SP: Papirus.

Noronha, A. P. P. (2002). Os problemas mais graves e mais freqüentes no uso dos testes psicológicos. Psicologia, Reflexão e Crítica, 15(1), 135-142.

Pergher, N. (2002). É possivel saber se o cliente está falando a verdade? In A. Teixeira, (Ed.), Ciência e comportamento: conhecer e avançar. ( Vol. 2). Santo André, SP: ESETec.

Sackett, P. R., \& Lievens, F. (2008). Personnel selection. Annual Review of Psychology, 59, 419-450.

Sampaio, J. R. (1998). Psicologia do trabalho em três faces. In J. R. Sampaio \& I. B. Goulart (Eds.), Psicologia do trabalho e gestão de recursos humanos: estudos contemporâneos. São Paulo: Casa do Psicólogo.

Santos, J. G. W., Franco, R. A., \& Miguel, C. F. (2003). Seleção de pessoal: Considerações preliminares sobre a perspectiva behaviorista radical. Psicologia, Reflexão e Crítica, 16(2), 235243.

Skinner, B. F. (1981). Ciência e comportamento humano. São Paulo: Martins Fontes.

Spector, P. E. (2003). Psicologia nas organizações. São Paulo: Saraiva.

Wanderley, W. M. (1985). Os testes psicológicos em seleção de pessoal: análise crítica dos conceitos e procedimentos utilizados. Arquivos Brasileiros de Psicologia Aplicada, 37(2), 16-31. 